\title{
Interferons, B Cells and Neutrophils: Innate and Adaptive Allies in Systemic Lupus Erythematosus
}

\author{
Alaa A A Mohamed ${ }^{1 *}$, Tamer A Gheita ${ }^{2}$ \\ ${ }^{1}$ Rheumatology, Rehabilitation and Physical Medicine department, Faculty of Medicine, Assiut \\ University, Assiut, Egypt
}

${ }^{2}$ Rheumatology Department, Faculty of Medicine, Cairo University, Cairo, Egypt

Received: March 01, 2018; Accepted: March 15, 2018; Published: April 07, 2018

*Corresponding author: Alaa Mohamed, MD, PhD, Assiut University Hospital, Assiut, 71515, Egypt. Tel: +201018554227; E-mail: a.a.a.mohamed@ aun.edu.eg

\begin{abstract}
Systemic lupus erythematosus (SLE) is clinically and immunologically heterogeneous with variable organ involvement, severity and therapeutic responses. B cells are known as mediators of disease manifestations. Therefore, disease control is targeted by inhibiting proliferation and inducing apoptosis of $\mathrm{B}$ cells via conventional cytotoxic drugs or newly developing biologics. However, the outcome of therapy is sometimes heterogeneous which further attracts to understand other immune mechanisms influencing B cell functions such as interferons (IFNs) cytokines and the innate cells, neutrophils. Successful management of SLE requires an understanding of how these factors interact, taking into consideration the patients' variations in these factors which might confer heterogeneity in disease outcome. In this review, it will be focused on the existing data in literature on the mutual influence between interferons, B cells and neutrophils in disease pathogenesis and the clinical impact in disease assessment and their potential blocking.
\end{abstract}

Keywords: Systemic Lupus Erythematosus; B Cells; Neutrophils; Cytokines and Inflammatory Mediators; Autoantigens and Autoantibodies

\section{Abbreviations}

SLE: Systemic Lupus Erythematosus; pDCs: Plasmacytoid Dendritic Cells ; TLRs: Toll-Like Receptors; IFNs: Interferons; BAFF: B-Cell Activating Factor; APRIL: A Proliferation-Induced Ligand; PBMCs: Peripheral Blood Mononuclear Cells; PB: Plasma blast; PCs: Plasma Cells; CSR: Class Switch Recombination; Ig: Immunoglobulins; BM: Bone Marrow; IL: Interleukin; BCR: B Cell Receptor; mAb: Monoclonal Antibodies; SHM: Somatic Hyper Mutation; AICDA: Activation-Induced Cytidine Deaminase; TNF- $\alpha$ : Tumor Necrosis Factor- $\alpha$; MyD88: Myeloid Differentiation Primary Response 88; IFNAR: Interferon Alpha Receptor; WT: Wild Type; TH: T Helper; IFNR:IFN Receptors; Ab: Antibody; ODN: Oligo Deoxy Nucleotides; NK: Natural Killer; NETs: Neutrophil Extracellular Traps; MZ: Marginal Zone; TACI: Transmembrane Activator and Calcium Modulator and Cyclophilin Ligand Interactor; LDGs: Low-Density Granulocytes; G-CSF:
Granulocyte Colony Stimulating Factor; GM-CSF: Granulocyte Macrophage Colony Stimulating Factor; PAD4:Peptidyl Arginine Deiminase-IV; ACPA: Anti-Citrullinated Peptide Antibodies; Siglec-1:Sialic Acid-binding Ig-like Lectin-1; UNGAL: Urinary Neutrophil Gelatinase-Associated Lipocalin.

\section{Introduction}

Systemic lupus erythematosus (SLE) is a multi-system autoimmune disease characterized by involvement of all organs in the body. The clinical features of the disease are heterogeneous and run in a remitting-relapsing course with variable prognosis [1]. SLE is characterized by the important role of B cells and the wide range of autoantibodies targeting particularly the nuclear antigens and mediating the disease $[1,2]$. B cells are targeted whether by standard cytotoxic drugs or by B-cell depletion therapy as biologics. However, the heterogeneity among patients in the clinical effects suggests the presence of underlying factors contributing to the development of B cells and their aberrant behaviour [3, 4]. Research has focused on the role of innate mechanisms such as plasmacytoid dendritic cells (pDCs), Tolllike receptors (TLRs), interferons (IFNs), neutrophils and gene mutations in the initiation and perpetuation of the disease [5-7].

IFNs are a big family composed of type-I that includes importantly IFN- $\alpha / \beta$ and type-II that includes IFN- $\gamma$ [8]. IFNlike molecules have also been described as type-III IFN, (IFN- $\lambda 1$, $\lambda 2$, and $\lambda 3$ ] [9].IFNs play a physiologically important role in the defense mechanism against viral and bacterial infection. They are secreted in response to activation of pathogen recognition receptors on the antigen presenting cells [10].A persistent mimicked antiviral response is appreciated in SLE in which IFNs drive autoimmune reactions [11]. IFNs expression and signature, mainly type-I and -II, have been confirmed in SLE and also linked to disease activity in some studies [12-14]. IFN blocking therapies have demonstrated evidence of efficacy [15]. Of note, neutrophils have grasped attention as newly discovered partners in SLE pathogenesis via synthesizing IFNs and other pro-inflammatory 
cytokines and enhancing autoantibodies production [16]. This review sheds the light on the interplay between IFNs, B cells and neutrophils for better elucidation of the comprehensive interaction between them.

\section{Interferons Enhance B cell Development and Immune Repertory}

Interferons protect B cells at various stages of development. One mechanism is through inducing the secretion of growth factors, B-cell activating factor (BAFF) and A proliferationinduced ligand (APRIL). In vitro and in vivo studies on healthy donors or patients treated with IFNs showed that upon exposure to IFNs, BAFF and APRIL are up regulated in peripheral blood mononuclear cells (PBMCs), granulocytes and other cell types [1720]. In BAFF transgenic mice model, excess BAFF acts as a rescuer to auto-reactive B cells that are normally deleted at the late T2 stage in the peripheral development; they mature and colonize the splenic follicles. Also, auto-reactive B cells normally deleted at the marginal zone are found to be rescued and repopulate on excess BAFF [21].BAFF also enhances plasma blast (PB) survival and differentiation to plasma cells (PCs) [22]. BAFF/APRIL assist in the class switch recombination (CSR) of immunoglobulin's (Ig) from $C(\mu)$ to $C(\gamma)$ and /or $C(\alpha)[18]$. IFN type-I also up regulates the growth factors co-receptor, heparan sulphate, on murine splenic B cells. Heparan sulphate is thought to play a significant role in B cell immune response since its removal abrogates antibody production in response to APRIL [23].

Noticeably, the effect of IFNs also involves stages of B cell development in bone marrow (BM). In SLE BM, transitional B cells, particularly $\mathrm{T} 2$, are shown to be significantly higher in IFNhigh SLE BM as compared to IFN-low SLE BM and healthy controls, which could be attributed to the high expression of BAFF induced by IFN- $\alpha$ in BM[24, 25].Furthermore, the memory fraction in BM showed significant reduction in the un switched memory CD27/ Ig D+ and expansion of the switched CD27/IgD- memory B cells in SLE high-IFN BM. This was linked to more autoantibodies and chemokine expression in the high-IFN BM and was associated with a parallel response in the memory B cells in the peripheral blood [24].

Contrarily, IFN type-I showed a selective inhibition of interleukin (IL)-7 dependent growths and proliferation of pre-B cell lines suggesting its regulatory role that allows the selective survival of immuno competent B lineage cells [26]

PCs are also thought to be influenced by factors conferring longevity. PCs reside in a BM niche that is composed of stoma cells and multipotent hematopoietic precursors as shown previously in the BM of animal models [27]. There has been great belief that long-lived PCs derived from memory B cells have the potential to re-enter the cell cycle if the niche environment changes [28]. Notably, the high expression of type-I IFN was confirmed in BM of SLE patients and was associated with increase in BAFF and APRIL levels [24]. However, modification of niche environment by high cytokines levels that might confer the longevity to PCs in $\mathrm{BM}$ warrants investigations.
IFNs also enhance the production of immunoglobulin's. In mice models, it was shown that TLR ligand that result in type-I IFN production cause $\mathrm{T}$ cell-independent antibody response. This response was associated with high titers of all IgG subclasses $[29,30]$. Moreover, it was noticed that the secondary immune response is preserved with type-I IFN priming indicating that type-I IFN induces long-term antibody production and memory function [30]. On the other hand, lack of type-I IFN was associated with absence of IgG's in pDCs-depleted human PBMCs after culturing with live influenza virus despite the presence of B cells at the end of culture where as virus-triggered pDCs induced B cell differentiation into PCs[31].

\section{Interferons Improve Proficiency of Autoimmune B Cells}

IFNs not only affect the development of B cells but also affect $B$ cell functions as summarized in Table 1. Type-I IFN lowers the threshold of stimulation of $\mathrm{B}$ cell receptor (BCR) and induces the expression of MHC-II, CD69, CD86 and CD25, thus potentiating the antigen presenting capacity of $\mathrm{B}$ cells as shown in splenic and BM B cells of the murine models. Additionally, it reduces the concentration and duration needed by anti- $\mu$ monoclonal antibodies $(\mathrm{mAb})$ to produce maximum BCR internalization probably via enhancing calcium influx following BCR stimulation [32]. (Table 1)

The influence of type-I IFNs encompasses the TLRs of B cells. CpG-mediated TLR-9 activation of healthy donors 'naive B cells increases the antigen presenting capacity. This results in IgM secretion with CSR and somatic hyper mutation (SHM), via activation-induced cytidine deaminase (AICDA) up regulation, and ultimately IgG production [33]. It also induces the differentiation of $\mathrm{CpG}$-activated naïve $\mathrm{B}$ cells into memory cells and increases the production of IL-1 $\beta$, IL-10, IL- 6 and tumor necrosis factor- $\alpha$ (TNF- $\alpha$ ) and myeloid differentiation primary response 88 (MyD88) expression with further enhancement of CpG function [34].

In this context, pristane treated interferon alpha receptor (IFNAR) 2-/- mice failed to produce IgG antibodies against immune complexes compared with pristane-treated wild type (WT) with no significant difference in IgM in both groups. Furthermore, IFNAR2-/- B cells failed to up regulate TLR7 and TLR9 and the responses to TLR7 and TLR9 stimulation were reduced after type-I IFN treatment [35]. IFNAR1-/- B cells also suffered a significant reduction in proliferation after TLR7 stimulation compared to WT B cells. Besides, the ability of B cells to produce cytokines after TLRs stimulation was markedly diminished in IFNAR1-/- B cells [36]. Deletion of IFN type-I receptors was associated with marked reduction in anti-erythrocyte antibodies, hemolytic anemia, anti-ds DNA antibodies, kidney disease and mortality in the knockout mice [37].However, these findings were contradictory to earlier findings in congenic lupus-prone mice lacking type-I IFN receptors which exhibited surprisingly worsening of lymph proliferation and end-organ damage [38]. This might be attributed to different responses to IFNs in different strains of murine models [39] 
It was observed that activated pDCs isolated from healthy donors, through their high IFN-I production, are the principal mediators of B cell differentiation into IgM, IgG and IgA secreting cells and up regulation of transcription factors Blimp-1 and XBP1[6].B cells adopt a B cell effector- 1 function, similar to T helper (TH)-1 function, which is facilitated by IFN- $\alpha$. It was noted that IFN- $\alpha$ increases STAT 4 activation and T-bet expression in healthy donors 'resting B cells which in turn leads to enhanced IFN- $\gamma$ expression in B cells in response to IL-12 or BCR and TLR-2 stimulation [40]

Whilst type-I IFN exerts their function as anti-viral, anticancer and anti-angiogenic through mediating apoptosis and up regulating proapoptotic genes [41], it protects B cells from apoptosis by PI3-kinase-Akt pathway which is downstream from IFN receptors (IFNR) and this function was abrogated by IFNR blockade [42]. In other words, IFN type-I works in favor of B cells by providing accumulated self-antigens and protecting them against apoptosis. In vitro studies showed that type-I IFN up regulates the surface expression of the adhesion molecule L-selectin in human B lymphoid Daudi cell line. L-selectin is essential in the migration of $\mathrm{B}$ and $\mathrm{T}$ cells to peripheral lymphoid tissues [43-45]. Therefore, type-I IFN boosts trafficking of B cells to peripheral lymph nodes.

Noticeably, B cell responses to IFN- $\gamma$ were shown to be more complex. While IFN- $\gamma$ plays an important role in T cellmediated activation of $\mathrm{B}$ cells during initiation of primary antibody response, it targets stimulated B cells inhibiting further stimulation and reducing IgM secretion [46, 47]

\section{B cells as Innate Proponents Preserve IFNs}

In certain circumstances, B cells play a role in the innate defense mechanism and cause increased production of IFNs by a way or another. Interestingly, CD20- antibody (Ab) was foundto affect human B cell biologyin vitro and enhances type-I IFNs production upon viral infection. IFNs production was confirmed to be not related to viral replication and specific for B cells with CD20-Ab dose dependent manner particularly early in treatment [48].B cells were also reported to produce type-I IFN in response to TLR7 and TLR9 stimulation [36].

B cells, induced by RNA-immune complexes, Oligo Deoxy Nucleotides (ODN) or herpes simplex virus, were noticed to increase IFN- $\alpha$ production when they are co-cultured with pDC's in a dose dependent manner compared with pDCs-only cultures. Clustering of pDCs and B cells in the co-cultures indicates cell to cell contact stimulation [49]. Also, CpG-stimulated B cells enhance IFN- $\alpha$ production by pDCs, though they cause inhibition of activated myeloid DCs and enhance apoptosis of this subset [50].

AB-cell subset, CD11a high FC $\gamma \mathrm{R}$ III high CD19+, was reported to be induced in the central and peripheral lymph organs of mice challenged with TLR ligand such as lip polysaccharide and CpGODN. This subset lacks high expression of MHC-II but rich in cytokines and cytokine receptors, and upon CD40 activation, they produce IL-1, IL-6 and IFN- $\gamma$. The production of IFN- $\gamma$ was high and comparable to natural killer (NK) cells [51].

\section{The Interplay between Neutrophils and the Mononuclear Cells}

Neutrophils have long been known for their roles as the first line of defense against microbial infection. They are the first cells recruit at sites of inflammation. They function as phagocytes and cause intracellular degradation of the microbes. Additionally, they release antimicrobial agents and form neutrophil extracellular traps (NETs) that limit and eliminate different microbes [52, 53].

The role of neutrophils extends to the enhancement and regulation of other immune cells. For example, LL-37 and heparin-binding protein, products of neutrophils, mediate recruitment of monocytes and subsequent augmentation of the immune response [54]. Moreover, heparin-binding protein and human neutrophil peptides 1-3 enhance the phagocytic activity of macrophages and trigger them to release TNF- $\alpha$ and IFN- $\gamma$ [55]. Also, DCs are attracted and activated by alarmins to produce augmentation of the immune response [56]. The story is more complex with $\mathrm{T}$ cells where neutrophils appear to activate or suppress $\mathrm{T}$ cells according to different contexts. The cross talk between both types of cells occurs via cytokines from both sides that affect the function of each other and via cell-to-cell contact [57].

\section{Neutrophils Outfit B Cells in the Lymphoid Tissues and Bone Marrow}

Neutrophils colonize physiologically around the marginal zone (MZ) areas of the spleen and in the perifollicular areas of the mesenteric lymph nodes in healthy donors where they interact with MZ B cells; therefore known as B cell-helper neutrophils [58]. However, in the pathological conditions such as SLE, the MZ is lost [59] and the neutrophils are noticed extensively infiltrating the germinal-center areas activating MZ B cells via contact-dependent and contact-independent mechanisms and their efficacy in B cell activation was comparable to that of CD4 T cells [58].Similar findings in WT and lupus prone mice, neutrophils reside in the perifollicular areas of the spleen in WT with more extension to the $\mathrm{T}$ cell zones in lupus prone mice [60]. The interaction between MZ B cells and B cell-helper neutrophils results in up regulation of AICDA gene which is responsible for inducing CSR and SHM $[58,61]$.

Immunoglobulin diversification and SHM are also the result of the contact independent effect of neutrophils on $B$ cells. Neutrophils are reported to secrete BAFF, APRIL and IL-21. B cell-helper neutrophils tend to express higher surface BAFF and release more soluble BAFF, APRIL and IL-21 than do conventional neutrophils [58]. Correspondingly, MZ B cells express mRNA for transmembrane activator and calcium modulator and cyclophilin ligand interactor (TACI) higher than naive B cells but comparable expression of BAFF receptors. Blocking of BAFF, APRIL or IL-21 receptors results in impaired $\operatorname{IgM}, \operatorname{IgG}$ and $\operatorname{IgA}$ production and poor development of effectors B cells [58, 62, 63].

Since neutrophils also enhance CD4 T cells proliferation and IFN $-\gamma$ production via BAFF, depletion of neutrophils resulted in 
dramatic reduction of BAFF and IFN- $\gamma$ levels, the numbers of CD4 $T$ cells, germinal center B cells and PCs together with diminished serum anti-ds DNA and immune complexes deposition in the murine kidneys [60].

The link between neutrophils and B cells was also prominent in the BM. The mature neutrophil fraction in SLE BM exhibits significantly higher IFN- $\alpha$, BAFF and APRIL expression which could not be attributed top DCs fractions and this finding was also noticed in the BM neutrophils of lupus prone mice [24].

\section{Neutrophils Are an Additional Source of IFN}

In vitro analysis of type-I IFN production in different peripheral blood leucocytes from healthy donors in response to different stimuli showed that neutrophils were the strongest producer of IFN- $\alpha$ in response to chromatin in a dose dependent manner. Of note, this response was shown to be variable among different individuals of SLE and healthy controls and higher percentage of IFN-producing neutrophils were obtained when neutrophils were cultured with the whole blood. As regarding CpG-ODN stimulation, pDCs produce much more IFNs but neutrophils' production is still comparable owing to their markedly higher abundance [64].

There has been also other evidence in the peripheral blood confirming that neutrophils are producers of IFNs. Low-density granulocytes (LDGs), a subset of neutrophils, have been identified in the mononuclear cell fraction in the peripheral blood of SLE patients and represent activated phenotype of neutrophils although they lack the phagocytic activity. They are characterized by their capacity to synthesize high levels of type-I IFNs and IFN- $\gamma[65,16]$. Stimulation of IFN- $\alpha$ production from neutrophils is enhanced by the additive effect of other cytokines such as granulocyte colony stimulating factor (G-CSF), granulocyte macrophage colony stimulating factor (GM-CSF) or IFN- $\alpha$ and results in up regulation of TLRs and DNA sensors. Moreover, it results in induction of NETosis that will be discussed below [64].

\section{Neutrophil Nuclear and Cytoplasmic Weapons}

NETosis is another way whereby neutrophils can influence B cells. NETosis is fundamentally neutrophil suicide committed to capture organisms through formation of NETs composed of non-condensed chromatin DNA in association with histones and granular protein. Neutrophils can be activated to produce NETs by ligands of TLRs, antibodies, chromatin and immune complexes $[66,67]$. NETs in SLE serve as type-I IFN inducer by activating pDCs as well as neutrophils $[68,64]$.

Furthermore, NETosis provide a novel source of autoantigens. The extrusion of intracellular components renders these autoantigens triggers of $\mathrm{B}$ cells to produce autoantibodies [7]. Moreover, NETs formation involves reactive oxygen species that modify DNA and proteins making them more immunogenic [69]. These modified proteins have been shown to produce more pathogenic antibodies in a variety of diseases such as SLE [70]. Of note, the pathogenicity of NETs depends on the integrity of their components to produce the damaging effects on the tissues [7]. Failure to degrade NETs was also found to be associated with higher levels of anti-NETs and anti-ds DNA autoantibodies and higher frequency of lupus nephritis [71]. This effect could be partially reversed by DNAse-I that degrade NETs whereas C1q and antibodies that bind NETs serve as protectors for NETs against degradation $[71,72]$.

NETosis requires posttranslational modification of histones to release chromatin by peptidyl arginine deiminase-IV (PAD4). Those citrullinated histones are thought to increase the load of citrullinated antigens and result in further increase in anticitrullinated histone antibodies [73]. The role of NETosis immunogenicity can be exemplified by a model proposed by Dwivedi and RadicforFelty's syndrome pathogenesis, in which neutrophils are responsible for increasing the pathogenicity of the disease, as compared to RA. Neutrophils extrude modified histones and chromatin that, in complex with bacteria, trigger autoantibodies formation which further target neutrophils antigens causing neutropenia and subsequent increase in the modified histones and autoantibodies [74]. It has been shown that citrullinated histones are targets of anti-citrullinated peptide antibodies (ACPA) and ACPA are capable of inducing NETosis in RA neutrophils [75-77]. Notably, histone modification particularly acetylation was noticed to enhance the immunostimulatory effect of NETs in SLE [78].

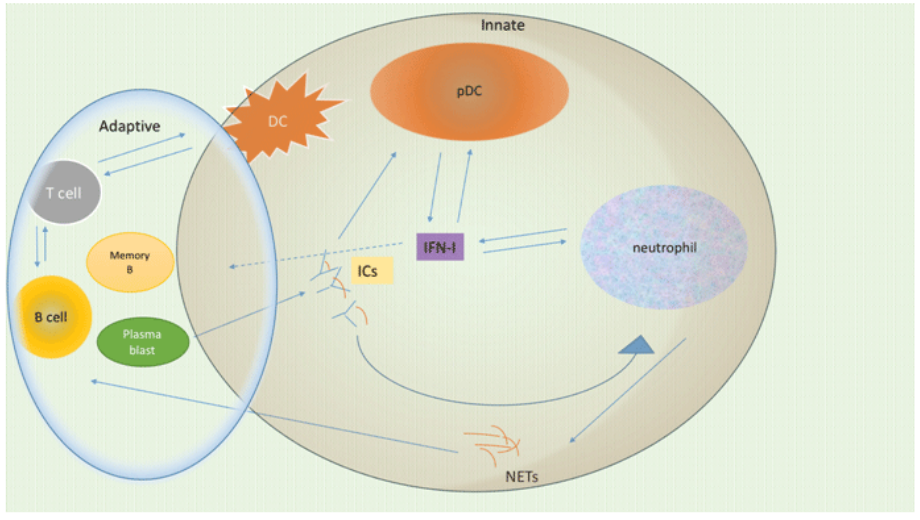

Figure 1: The integration between the innate and adaptive immune cells in SLE

IFN-I, interferon type I; PDC, plasmacytoid dendritic cell; DC, dendritic cell, ICs, immune complexes; NETs, neutrophil extracellular traps. 


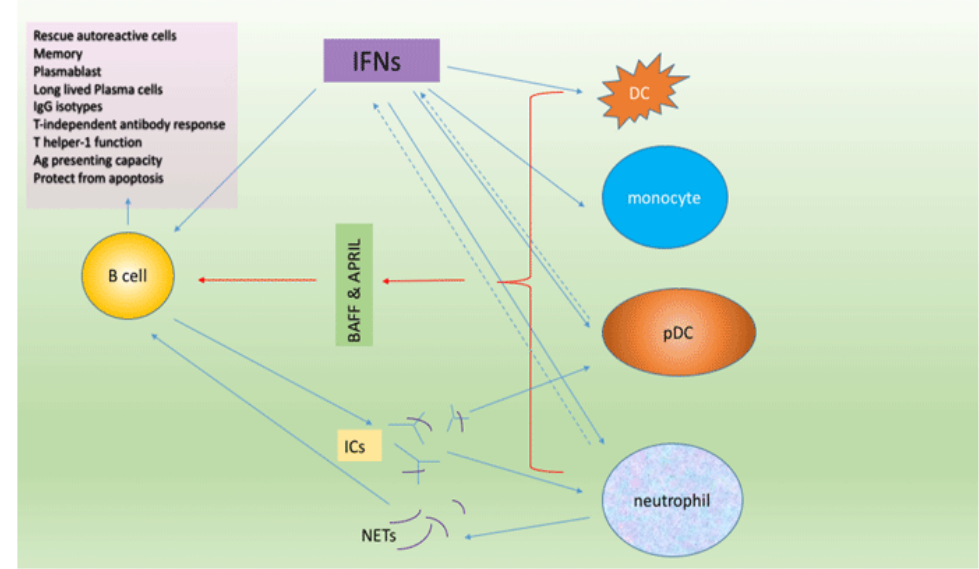

Figure 2: The interplay between neutrophils, B cells and IFNs

IFNs, interferons; BAFF, B-cell activating factor; APRIL, A proliferation induced ligand; DC, dendritic cell; ICs, immune complexes; NETs, neutrophil extracellular traps; IgG, immunoglobulin G; Ag, antigen.

The interaction between the innate and adaptive immunity is shown in Figure 1 and the interplay between neutrophils, B cells and IFNs is highlighted in Figure 2. (Figure 1,2)

\section{Clinical Utility}

The unabated secretion of IFNs has direct and indirect toxic effects on different body systems as summarized in Figure 3. Owing to the fact that IFNs, particularly IFN- $\alpha$, are pivotal cytokines in the pathogenesis of SLE, they have an indispensable importance in aiding the diagnosis and follow up of disease activity, and a potential to antagonize to reverse disease progression. IFN- $\alpha$ level were first measured in 1980's and were found in SLE correlating with disease activity $[79,80]$. However, the measurement of IFN induced genes is considered more sensitive than direct measurements of IFNs [81, 12, 13]. IFNinduced genes were observed correlating with disease activity [82]. Nevertheless, they fail to longitudinally correlate with changes in disease activity [83].] (Figure 3)

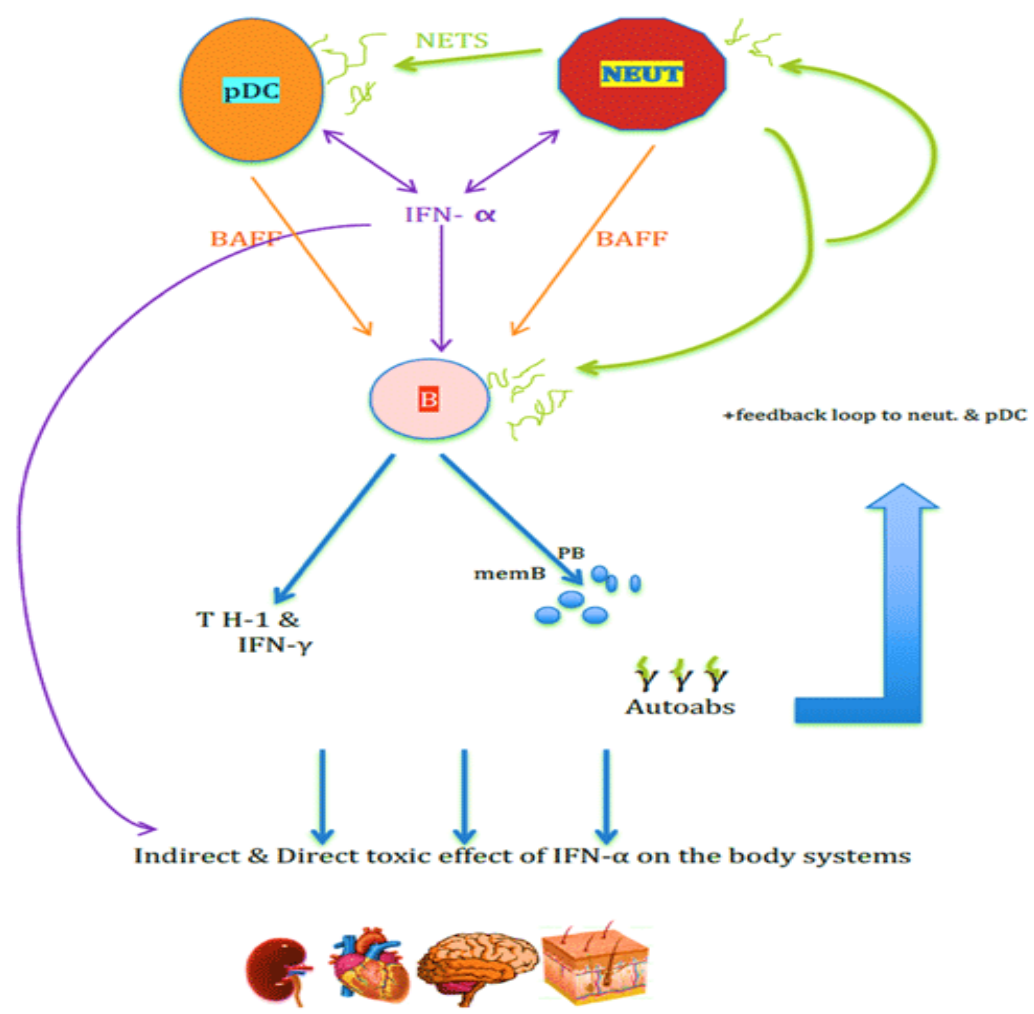

Figure 3: Summary of the direct and indirect toxic effects of IFNs on different body systems4 


\begin{tabular}{|c|c|c|}
\hline IFNs effects & B cell Development & B cell Functionality \\
\hline $\begin{array}{l}\text { ÎBAFF \& APRIL }(15,18,20) \\
\text { Î IL-10, IL-1 } \beta, \text { IL-6 \& TNF- } \alpha(32)\end{array}$ & Rescue autoreactive B cells from deletion (19) & $\begin{array}{l}\text { Lowering BCR -stimulation threshold } \\
\text { (30) }\end{array}$ \\
\hline Î Heparansulphate(21) & Enhance plasmablast cells survival and differentiation (20) & Î Antigen presenting capacity $(30,31)$ \\
\hline Î MHC-II, CD69, CD86 \& CD25 (30) & Class switch recombination (16) & $\begin{array}{l}\text { B cell effector-1 function and IFN- } \gamma \\
\text { expression (38) }\end{array}$ \\
\hline Î AICDA (16) & Increase responsiveness to APRIL (21) & $\begin{array}{l}\text { Trafficking of B cells to the lymph } \\
\text { nodes (41) }\end{array}$ \\
\hline Î L-selectin (41) & $\begin{array}{l}\text { Reduction in pro/pre-B and Î in transitional and follicular } \\
\text { B cells in BM (22) }\end{array}$ & $\begin{array}{l}\text { Î Apoptosis \& accumulation of self- } \\
\text { antigens (39) }\end{array}$ \\
\hline \multirow[t]{4}{*}{ Î PI3-kinase-Akt pathway via IFNR (40) } & $\begin{array}{l}\text { Î Switched CD27/IgD- memory B in BM and peripheral } \\
\text { blood (22) }\end{array}$ & Protect B cells from apoptosis (40) \\
\hline & ? Conferring longevity to PCs (26) & \\
\hline & $\begin{array}{l}\text { Acquire plasma cell phenotype and immunoglobulins } \\
\text { secretion (6) }\end{array}$ & \\
\hline & Î Primary and secondary antibody response $(27,28)$ & \\
\hline
\end{tabular}

Sialic acid-binding Ig-like lectin-1 (Siglec-1) is a type-I IFN induced gene. Measuring of the Siglec-1 protein on monocytes was found to correlate with disease activity and remission after therapy [84, 85].FC $\gamma \mathrm{R} 1$ (CD64) was also thought to be a surrogate marker reflecting type-I IFN activity in the peripheral blood of SLE patients and its expression parallels renal disease[86, 87]. Lately, the hypomethylation of two $\mathrm{CpG}$ sites within the promoter region of IFFI44L is considered a highly sensitive and specific diagnostic marker for SLE as it was seen significantly higher in SLE compared to healthy controls and other autoimmune diseases. Additionally, the methylation levels were significantly lower in SLE with renal damage as opposed to those without and conversely, methylation increased in remission [88].

IFN type-I, and its cytotoxic-driven reaction, is responsible for what is known as interface dermatitis [89].MxA, a surrogate marker for local production of type-I IFN, was shown significantly higher in sub acute and chronic forms of lupus skin lesions compared to healthy controls, however, the chronic discoid lupus exhibited tremendously more MxA, which implies that type-I IFN together with the cytotoxic lymphocytes are responsible for the scarring events in these lesions[90].Additionally, MxA distribution in different cutaneous lupus lesions reflects the histological heterogeneity of the inflammatory reactions in these forms $[91,92]$.

The most important type of IFNs implicated in the pathogenesis SLE appears to be IFN- $\alpha$, this was evident by the neutralization of IFN signature in serum assays and clinical trials by anti-IFN $\alpha$ strategies [15]. Anti-IFN $\alpha$ strategies are directed towards blocking IFN- $\alpha$ by neutralizing antibodies or blocking its receptors.
Rontalizumab and Sifalimumab are anti-IFN $\alpha$ monoclonal antibodies that bind to and specifically neutralize most IFN $\alpha$ subtypes. Results of phase 1 trials with Rontalizumab in mildly active SLE showed a rapid decline in the expression of interferon regulated genes but not in the levels of IFN-inducible proteins or levels of anti-ds-DNA and anti-extractable nuclear antibodies[93]. Results of phase 2 trials in patients with moderately to severely active extra-renal SLE did not achieve reduction in disease activity, however, the pre-specified group of low-IFN signature patients had a significant decline in SLE response index compared to placebo and achieved more frequently prednisone dose reduction [15]. Results of phase 1 clinical trials with Sifalimumab in moderately active SLE showed dose-dependent inhibition of type-I IFN signature in whole blood and corresponding changes in related proteins in the affected skin. There was also a trend towards improvement in disease activity in Sifalimumab-treated versus placebo-treated subjects [94]. Furthermore, Sifalimumab showed previously a trend towards suppression of the expression of BAFF, TNF $\alpha$, IL-10, IL-1ßand GM-CSF [95], and a trend towards normal complement (C3 or C4) levels [96].

Blocking IFNAR inhibits the activity of all IFN-I types. Therefore, both efficacy and toxicity might be higher compared to anti-IFN $\alpha$ mAb's. Phase 2 clinical trials to evaluate MEDI-546 (Anifrolumab) -IFNAR blocker-in SLE have shown consistent efficacy with reduction in all global and organ specific measures particularly in patients with high baseline IFN-signature [97].

Immunizing SLE patients with IFN $\alpha$-Kinoid, recombinant conjugated human IFN $\alpha$, produces polyclonal neutralizing antiIFN $\alpha$ antibodies. This approach was effective in a lupus murine model to prevent disease flare [98]. Results of phase I/II clinical 
trials have shown significant negative correlation between the neutralizing anti- IFN $\alpha$ titers and IFN scores. There was also associated reduction in B-cell transcripts [99].

TLR 7 and 9- stimulation on pDCs is claimed to be responsible for the reduced ability of gluco corticoids to suppress IFN pathways in SLE. Blocking of these receptors is expected to establish the sensitivity of pDCs to the blocking effects of gluco corticoids. The blocking strategies of potential use in SLE are the TLR 7/8/9 antagonists - CPG-52364 and IMO-8400 -as well as the TLR7/9 antagonists [15, 100-102].

The neutrophil products have also had clinical implications The most prominent example is $\alpha$-defensin. It was found significantly higher in SLE patients compared to healthy controls, and the high serum levels correlated significantly with disease activity [103]. However, other study described $\alpha$-defensins as indicators of lupus nephritis per se [104]. Although anti-defensin antibodies were found in the sera of SLE with active and inactive disease, they were significantly higher in active SLE [103].

NETs were seen in specimens of lupus nephritis and the percentage of the glomeruli infiltrated by netting neutrophils were higher in class IV than class III lupus nephritis and also correlated with the activity index according to the WHO classification. Contrarily, no NETs were observed in renal specimen of fulminant Henoch-Schonlein purpura[16].Additional evidence, supporting that neutrophil components are contributing to renal damage and lupus nephritis, comes from many studies undertaking the investigation of urinary neutrophil gelatinase-associated lipocalin (UNGAL) in lupus nephritis. UNGAL is proposed to be a marker of SLE and an indicator of renal activity, moreover, the UNGAL levels were seen correlating to the lupus nephritis grading [105-110]. Anti-lipocalin IgG has also been reported as a new marker in SLE that can assist in the diagnosis of SLE with high sensitivity and specificity in disease distinguishes [111].

Neutrophils and their production of high amounts of type-I IFNs have shown a clinical impact and an increase in the burden of SLE as regarding the vascular cytotoxicity since LDGs correlated with the development of premature cardiovascular disease through their potential to induce vascular damage and to inhibit vascular repair [65].

It is also important to note that some cutaneous forms of the disease involve an auto-inflammatory process in which neutrophils represent the major aetiologic factors, for example, bullous lupus erythematosus, urticarial vasculitis and early stages of specific cutaneous lupus, in addition to some neutrophilic dermatosis reported to occur in lupus erythematosus [112,113].

The analysis of skin biopsies from different cutaneous lupus forms revealed the presence of NETs particularly in the papillary dermis, around the blood vessels and adnexae including hair follicles and the eccrine glands. In lupus panniculitis, the infiltration of NETs was seen in the lobular adipose tissue and the reticular dermis. NETs aggregate in the skin express LL-37-dsDNA complexes, which are mostly the triggering for the formation of increased levels of anti-ds DNA in the sera[16].Herein, we note to the effect of Antimalarial drugs in decreasing the oxidative loads of NETs and modifying disease manifestations [114]

As IL-17 is proposed to have a role in the pathogenesis of lupus, it is important to report that, besides Th17, neutrophils are an additional source of IL-17 and LDGs were externalizing IL17 in high proportions during NETs formation. Neutrophils are reported to be the most IL-17 expressing cells in lupus skin [16, $115,116]$.

PAD activity, which initiates the formation of NETs, is of a clinical importance as an epigenetic marker for autoantibody stimulation $[117,74]$. There is a potential to inhibit this enzyme to ameliorate the disease as was shown in various lupus models $[118,119]$.

Most of the biologics used in SLE are mainly targeting B cells. The mechanism by which they combat the auto reactive $B$ cells is diverse. Some of B-cell targeted therapies are directed towards the surface molecules such as anti-CD20 (Rituximab and Ocrelizumab) and anti-CD22 (Epratuzumab) [120-122]. Others target the growth factors, BAFF and APRIL, such as Belimumab, Atacicept, Blisibimod and Tabalumab [123, 124]. Also, immunoglobulin receptor antagonist (Abetimus sodium), anti-CD40L and proteasome antagonist (Bortezomib) have been tried in SLE [125-127]. The heterogeneity in the efficacy of anti-B cell therapies reflects the heterogeneity among lupus patients in the pathogenesis of the disease which in turn warrants understanding the magnitude of interplay between multiple pillars in the pathogenesis of SLE.

\section{Concluding Remarks}

This review aims to deepen the understanding of the innate immunity role, exemplified in IFNs and neutrophils, in the development of SLE by direct and indirect effects on enhancing the adaptive immunity, particularly B cells. The heterogeneity in disease outcomes with different therapeutic modalities warrants to pinpoint and abate the immunological deficit with the major aberrations. Therefore, we hope that disease progression is limited by the comprehensive development in the assessment and monitoring of the innate and adaptive allies together, hence, targeted therapies are individualized for patients with different clinical and immunological phenotypes.

\section{References}

1. Hochberg MC, Boyd RE, Ahearn JM, Arnett FC, Bias WB, Provost TT, et al. Systemic lupus erythematosus: a review of clinico-laboratory features and immunogenetic markers in 150 patients with emphasis on demographic subsets. Medicine (Baltimore). 1985; 64(5):285295.

2. Hanly JG, Thompson K, McCurdy G, Fougere L, Theriault C, Wilton K. Measurement of autoantibodies using multiplex methodology in patients with systemic lupus erythematosus. J Immunol Methods. 2010; 352(1-2):147-152. doi: 10.1016/j.jim.2009.10.003.

3. Merrill J, Buyon J, Furie R, Latinis K, Gordon C, Hsieh HJ, et al. Assessment of flares in lupus patients enrolled in a phase II/III study of rituximab (EXPLORER). Lupus. 2011; 20(7):709-716. doi:10.1177/0961203310395802. 
4. Thanou A, Merrill JT. Treatment of systemic lupus erythematosus: new therapeutic avenues and blind alleys. Nat Rev Rheumatol. 2014; 10(1):23-34. doi:10.1038/nrrheum.2013.145.

5. Yasutomo K, Horiuchi T, Kagami S, Tsukamoto H, Hashimura C, Urushihara M, et al. Mutation of DNASE1 in people with systemic lupus erythematosus. Nat Genet. 2001; 28(4):313-314. doi:10.1038/91070.

6. Douagi I, Gujer C, Sundling C, Adams WC, Smed-Sorensen A, Seder RA et al. Human B cell responses to TLR ligands are differentially modulated by myeloid and plasmacytoid dendritic cells. J Immunol. 2009; 182(4):1991-2001. doi:10.4049/jimmunol.0802257.

7. Yu Y, Su K. Neutrophil Extracellular Traps and Systemic Lupus Erythematosus. J Clin Cell Immunol. 2013; 4:139. doi:10.4172/21559899.1000139.

8. Pestka S, Krause CD, Walter MR. Interferons, interferon-like cytokines, and their receptors. Immunol Rev. 2004; 202:8-32. doi:10.1111/j.0105-2896.2004.00204.x.

9. Sheppard P, Kindsvogel W, Xu W, Henderson K, Schlutsmeyer S, Whitmore TE, et al. IL-28, IL-29 and their class II cytokine receptor IL-28R. Nature immunology. 2003; 4(1):63-68. doi:10.1038/ni873.

10. Kopitar-Jerala N. The Role of Interferons in Inflammation and Inflammasome Activation. Front immunol. 2017; 8:873. doi:10.3389/ fimmu.2017.00873

11. Crow MK. Type I interferon in the pathogenesis of lupus. J immunol 2014; 192(12):5459-5468. doi:10.4049/jimmunol.1002795

12. Bennett L, Palucka AK, Arce E, Cantrell V, Borvak J, Banchereau $\mathrm{J}$ et al. Interferon and granulopoiesis signatures in systemic lupus erythematosus blood. J Exp Med. 2003; 197(6):711-723. doi:10.1084/jem.20021553.

13. Kirou KA, Lee C, George S, Louca K, Peterson MG, Crow MK. Activation of the interferon-alpha pathway identifies a subgroup of systemic lupus erythematosus patients with distinct serologic features and active disease. Arthritis Rheum. 2005; 52(5):14911503. doi:10.1002/art.21031.

14. Hua J, Kirou K, Lee C, Crow MK. Functional assay of type I interferon in systemic lupus erythematosus plasma and association with anti-RNA binding protein autoantibodies. Arthritis Rheum. 2006; 54(6):1906-1916. doi:10.1002/art.21890.

15. Kirou KA, Gkrouzman E. Anti-interferon alpha treatment in SLE. Clin Immunol. 2013; 148(3):303-312. doi:10.1016/j.clim.2013.02.013.

16. Villanueva E, Yalavarthi S, Berthier CC, Hodgin JB, Khandpur R, Lin $\mathrm{AM}$ et al. Netting neutrophils induce endothelial damage, infiltrate tissues, and expose immunostimulatory molecules in systemic lupus erythematosus. J Immunol. 2011; 187(1):538-552. doi:10.4049/ jimmunol.1100450.

17. Krumbholz M, Faber H, Steinmeyer F, Hoffmann LA, Kumpfel $T$, Pellkofer $\mathrm{H}$ et al. Interferon-beta increases BAFF levels in multiple sclerosis: implications for B cell autoimmunity. Brain. 2008; 131(Pt 6):1455-1463. doi: 10.1093/brain/awn077.

18. Litinskiy MB, Nardelli B, Hilbert DM, He B, Schaffer A, Casali P et al. DCs induce CD40-independent immunoglobulin class switching through BLyS and APRIL. Nat Immunol. 2002; 3(9):822-829. doi:10.1038/ni829.

19. Buchanan R, Popowych Y, Dagenais C, Arsic N, Mutwiri GK, Potter AA, et al. Interferon-gamma and B-cell Activating Factor (BAFF) promote bovine B cell activation independent of TLR9 and T-cell signaling. Vet Immunol Immunopathol. 2012; 145(1-2):453-463. doi:10.1016/j. vetimm.2012.01.001

20. Woo SJ, Im J, Jeon JH, Kang SS, Lee MH, Yun CH, et al. Induction of BAFF expression by IFN-gamma via JAK/STAT signaling pathways in human intestinal epithelial cells. J Leukoc Biol. 2013; 93(3):363-368. doi:10.1189/jlb.0412210.

21. Thien M, Phan TG, Gardam S, Amesbury M, Basten A, Mackay F, et al. Excess BAFF rescues self-reactive B cells from peripheral deletion and allows them to enter forbidden follicular and marginal zone niches. Immunity. 2004; 20(6):785-798. doi:10.1016/j. immuni.2004.05.010.

22. MacLennan I, Vinuesa C. Dendritic cells, BAFF, and APRIL: innate players in adaptive antibody responses. Immunity. 2002; 17(3):235 238.

23. Jarousse N, Trujillo DL, Wilcox-Adelman S, Coscoy L. Virallyinduced upregulation of heparan sulfate on B cells via the action of type I IFN. J Immunol. 2011; 187(11):5540-5547. doi:10.4049/ jimmunol.1003495.

24. Palanichamy A, Bauer JW, Yalavarthi S, Meednu N, Barnard J, Owen T, et al. Neutrophil-mediated IFN activation in the bone marrow alters B cell development in human and murine systemic lupus erythematosus. J Immunol. 2014; 192(3):906-918. doi:10.4049/ jimmunol.1302112.

25. Sasaki Y, Casola S, Kutok JL, Rajewsky K, Schmidt-Supprian M. TNF family member B cell-activating factor (BAFF) receptor-dependent and -independent roles for BAFF in B cell physiology. Journal of immunology. 2004;173(4):2245-2252.

26. Wang J, Lin $\mathrm{Q}$, Langston $\mathrm{H}$, Cooper MD. Resident bone marrow macrophages produce type 1 interferons that can selectively inhibit interleukin-7-driven growth of B lineage cells. Immunity. 1995; $3(4): 475-484$

27. Tokoyoda K, Egawa T, Sugiyama T, Choi BI, Nagasawa T. Cellular niches controlling B lymphocyte behavior within bone marrow during development. Immunity. 2004; 20(6):707-718. doi:10.1016/j. immuni.2004.05.001.

28. Tooze RM. A replicative self-renewal model for long-lived plasma cells: questioning irreversible cell cycle exit. Front Immunol. 2013; 4:460. doi:10.3389/fimmu.2013.00460.

29. Swanson CL, Wilson TJ, Strauch P, Colonna M, Pelanda R, Torres RM. Type I IFN enhances follicular B cell contribution to the T cellindependent antibody response. J Exp Med. 2010; 207(7):14851500. doi:10.1084/jem.20092695.

30. Le Bon A, Schiavoni G, D’Agostino G, Gresser I, Belardelli F, Tough DF. Type i interferons potently enhance humoral immunity and can promote isotype switching by stimulating dendritic cells in vivo. Immunity. 2001; 14(4):461-470.

31. Jego G, Palucka AK, Blanck JP, Chalouni C, Pascual V, Banchereau J. Plasmacytoid dendritic cells induce plasma cell differentiation through type I interferon and interleukin 6. Immunity. 2003; 19(2):225-234.

32. Braun D, Caramalho I, Demengeot J. IFN-alpha/beta enhances BCRdependent B cell responses. Int Immunol. 2002; 14(4):411-419.

33. Jiang W, Lederman MM, Harding CV, Rodriguez B, Mohner RJ, Sieg SF. TLR9 stimulation drives naive B cells to proliferate and to 
attain enhanced antigen presenting function. European journal of immunology. 2007; 37(8):2205-2213. doi:10.1002/eji.200636984.

34. Giordani L, Sanchez M, Libri I, Quaranta MG, Mattioli B, Viora M. IFNalpha amplifies human naive B cell TLR-9-mediated activation and Ig production. J Leukoc Biol. 2009; 86(2):261-271. doi:10.1189/ jlb.0908560.

35. Thibault DL, Graham KL, Lee LY, Balboni I, Hertzog PJ, Utz PJ. Type I interferon receptor controls B-cell expression of nucleic acid-sensing Toll-like receptors and autoantibody production in a murine model of lupus. Arthritis Res Ther. 2009; 11(4):R112. doi:10.1186/ar2771.

36. Green NM, Laws A, Kiefer K, Busconi L, Kim YM, Brinkmann MM, et al. Murine B cell response to TLR7 ligands depends on an IFN-beta feedback loop. immunol. 2009; 183(3):1569-1576. doi:10.4049/ jimmunol.0803899.

37. Santiago-Raber ML, Baccala R, Haraldsson KM, Choubey D, Stewart TA, Kono DH, et al. Type-I interferon receptor deficiency reduces lupus-like disease in NZB mice. J Exp Med. 2003; 197(6):777-788. doi:10.1084/jem.20021996.

38. Hron JD, Peng SL. Type I IFN protects against murine lupus. J immunol. 2004; 173(3):2134-2142.

39. Braun D, Geraldes P, Demengeot J. Type I Interferon controls the onset and severity of autoimmune manifestations in lpr mice. J Autoimmun. 2003; 20(1):15-25.

40. de Goer de Herve MG, Durali D, Dembele B, Giuliani M, Tran TA Azzarone B, et al. Interferon-alpha triggers B cell effector 1 (Be1) commitment. PLoS one. 2011; 6(4):e19366. doi:10.1371/journal. pone.0019366.

41. Chawla-Sarkar M, Lindner DJ, Liu YF, Williams BR, Sen GC, Silverman $\mathrm{RH}$ et al. Apoptosis and interferons: role of interferon-stimulated genes as mediators of apoptosis. Apoptosis: an international journal on programmed cell death. 2003; 8(3):237-249.

42. Badr G, Saad H, Waly H, Hassan K, Abdel-Tawab H, Alhazza IM, et al. Type I interferon (IFN-alpha/beta) rescues B-lymphocytes from apoptosis via PI3Kdelta/Akt, Rho-A, NFkappaB and Bcl2/Bcl(XL). Cell Immunol. 2010; 263(1):31-40. doi:10.1016/j cellimm.2010.02.012.

43. Evans SS, Collea RP, Appenheimer MM, Gollnick SO. Interferon-alpha induces the expression of the L-selectin homing receptor in human $\mathrm{B}$ lymphoid cells. The Journal of cell biology. 1993; 123(6 Pt 2):18891898.

44. Reichert RA, Gallatin WM, Weissman IL, Butcher EC. Germinal center B cells lack homing receptors necessary for normal lymphocyte recirculation. The Journal of experimental medicine. 1983;157(3):813-827.

45. Dailey MO, Gallatin WM, Weissman IL. The in vivo behavior of T cell clones: altered migration due to loss of the lymphocyte surface homing receptor. The Journal of molecular and cellular immunology: JMCI. 1985; 2(1):27-36.

46. Johnson-Leger C, Hasbold J, Holman M, Klaus GG. The effects of IFN-gamma on CD40-mediated activation of B cells from X-linked immunodeficient or normal mice. J Immunol. 1997; 159(3):11501159.

47. Abed NS, Chace JH, Fleming AL, Cowdery JS. Interferon-gamma regulation of $\mathrm{B}$ lymphocyte differentiation: activation of $\mathrm{B}$ cells is a prerequisite for IFN-gamma-mediated inhibition of $\mathrm{B}$ cell differentiation. Cell immunol. 1994; 153(2):356-366. doi:10.1006/ cimm.1994.1034

48. Xu D, Staedman A, Zhang L. CD20 antibody primes B lymphocytes for type I interferon production. PLoS one. 2013; 8(6):e67900. doi:10.1371/journal.pone.0067900.

49. Berggren 0, Hagberg N, Weber G, Alm GV, Ronnblom L, Eloranta ML. B lymphocytes enhance interferon-alpha production by plasmacytoid dendritic cells. Arthritis Rheum. 2012; 64(10):34093419. doi:10.1002/art.34599.

50. Maddur MS, Kaveri SV, Bayry J. Dual role of CpG-stimulated B cells in the regulation of dendritic cells: comment on the article by Berggren et al. Arthritis and rheumatism. 2013;65(8):2215-6. doi:10.1002/ art.38004.

51. Bao Y, Liu X, Han C, Xu S, Xie B, Zhang Q et al. Identification of IFNgamma-producing innate B cells. Cell research. 2014; 24(2):161176. doi:10.1038/cr.2013.155.

52. Nathan C. Neutrophils and immunity: challenges and opportunities. Nat Rev Immunol. 2006; 6(3):173-182. doi:10.1038/nri1785.

53. Papayannopoulos V, Zychlinsky A. NETs: a new strategy for using old weapons. Trends Immunol. 2009; 30(11):513-521. doi:10.1016/j. it.2009.07.011.

54. Soehnlein O, Zernecke A, Eriksson EE, Rothfuchs AG, Pham CT, Herwald $\mathrm{H}$, et al. Neutrophil secretion products pave the way for inflammatory monocytes. Blood. 2008; 112(4):1461-1471. doi:10.1182/blood-2008-02-139634.

55. Soehnlein O, Kai-Larsen Y, Frithiof R, Sorensen OE, Kenne E, Scharffetter-Kochanek K, et al. Neutrophil primary granule proteins HBP and HNP1-3 boost bacterial phagocytosis by human and murine macrophages. J Clin Invest. 2008; 118(10):3491-3502. doi:10.1172/ JCI35740.

56. Yang D, de la Rosa G, Tewary P, Oppenheim JJ. Alarmins link neutrophils and dendritic cells. Trends Immunol. 2009; 30(11):531537. doi:10.1016/j.it.2009.07.004.

57. Muller I, Munder M, Kropf P, Hansch GM. Polymorphonuclear neutrophils and $\mathrm{T}$ lymphocytes: strange bedfellows or brothers in arms? Trends Immunol. 2009; 30(11):522-530. doi:10.1016/j. it.2009.07.007.

58. Puga I, Cols M, Barra CM, He B, Cassis L, Gentile M, et al. B cellhelper neutrophils stimulate the diversification and production of immunoglobulin in the marginal zone of the spleen. Nat Immunol. 2012; 13(2):170-180. doi:10.1038/ni.2194.

59. Zhou Z, Niu H, Zheng YY, Morel L. Autoreactive marginal zone B cells enter the follicles and interact with CD4+ T cells in lupus-prone mice. BMC Immunol. 2011; 12:7. doi:10.1186/1471-2172-12-7.

60. Coquery CM, Wade NS, Loo WM, Kinchen JM, Cox KM, Jiang C, et al. Neutrophils contribute to excess serum BAFF levels and promote CD4+ T cell and B cell responses in lupus-prone mice. PloS one. 2014; 9(7):e102284. doi:10.1371/journal.pone.0102284.

61. Muramatsu M, Kinoshita K, Fagarasan S, Yamada S, Shinkai Y, Honjo T. Class switch recombination and hypermutation require activationinduced cytidine deaminase (AID), a potential RNA editing enzyme. Cell. 2000; 102(5):553-563.

62. Ozaki K, Spolski R, Ettinger R, Kim HP, Wang G, Qi CF, et al. Regulation of B cell differentiation and plasma cell generation by IL-21, a novel inducer of Blimp-1 and Bcl-6. J immunol. 2004; 173(9):5361-5371. 
63. Avery DT, Deenick EK, Ma CS, Suryani S, Simpson N, Chew GY, et al. B cell-intrinsic signaling through IL-21 receptor and STAT3 is required for establishing long-lived antibody responses in humans. J Exp Med. 2010; 207(1):155-171. doi:10.1084/jem.20091706.

64. Lindau D, Mussard J, Rabsteyn A, Ribon M, Kotter I, Igney A, et al. TLR9 independent interferon alpha production by neutrophils on NETosis in response to circulating chromatin, a key lupus autoantigen. Ann Rheum Dis. 2014; 73(12):2199-2207. doi:10.1136/ annrheumdis-2012-203041.

65. Denny MF, Yalavarthi S, Zhao W, Thacker SG, Anderson M, Sandy AR, et al. A distinct subset of proinflammatory neutrophils isolated from patients with systemic lupus erythematosus induces vascular damage and synthesizes type I IFNs. Journal of immunology. 2010; 184(6):3284-3297. doi:10.4049/jimmunol.0902199.

66. Brinkmann V, Reichard U, Goosmann C, Fauler B, Uhlemann Y, Weiss DS, et al. Neutrophil extracellular traps kill bacteria. Science. 2004; 303(5663):1532-1535. doi:10.1126/science.1092385.

67. Garcia-Romo GS, Caielli S, Vega B, Connolly J, Allantaz F, Xu Z, et al. Netting neutrophils are major inducers of type I IFN production in pediatric systemic lupus erythematosus. Sci Transl Med. 2011; 3(73):73ra20. doi:10.1126/scitranslmed.3001201.

68. Lande R, Ganguly D, Facchinetti V, Frasca L, Conrad C, Gregorio J, et al. Neutrophils activate plasmacytoid dendritic cells by releasing selfDNA-peptide complexes in systemic lupus erythematosus. Sci Transl Med. 2011; 3(73):73ra19. doi:10.1126/scitranslmed.3001180.

69. Fuchs TA, Abed U, Goosmann C, Hurwitz R, Schulze I, Wahn V, et al. Novel cell death program leads to neutrophil extracellular traps. J Cell Biol. 2007; 176(2):231-241. doi:10.1083/jcb.200606027.

70. Kurien BT, Scofield RH. Autoimmunity and oxidatively modified autoantigens. Autoimmun Rev. 2008; 7(7):567-573. doi:10.1016/j. autrev.2008.04.019.

71. Hakkim A, Furnrohr BG, Amann K, Laube B, Abed UA, Brinkmann $\mathrm{V}$ et al. Impairment of neutrophil extracellular trap degradation is associated with lupus nephritis. Proc Natl Acad Sci U S A. 2010; 107(21):9813-9818. doi:10.1073/pnas.0909927107.

72. Leffler J, Martin M, Gullstrand B, Tyden H, Lood C, Truedsson $\mathrm{L}$, et al. Neutrophil extracellular traps that are not degraded in systemic lupus erythematosus activate complement exacerbating the disease. J Immunol. 2012; 188(7):3522-3531. doi:10.4049/ jimmunol.1102404.

73. Dwivedi N, Upadhyay J, Neeli I, Khan S, Pattanaik D, Myers L, et al Felty's syndrome autoantibodies bind to deiminated histones and neutrophil extracellular chromatin traps. Arthritis Rheum. 2012; 64(4):982-992. doi:10.1002/art.33432.

74. Dwivedi N, Radic M. Citrullination of autoantigens implicates NETosis in the induction of autoimmunity. Ann Rheum Dis. 2014; 73(3):483-491. doi:10.1136/annrheumdis-2013-203844.

75. Sur Chowdhury C, Giaglis S, Walker UA, Buser A, Hahn S, Hasler P. Enhanced neutrophil extracellular trap generation in rheumatoid arthritis: analysis of underlying signal transduction pathways and potential diagnostic utility. Arthritis Res Ther. 2014; 16(3):R122. doi:10.1186/ar4579.

76. Pratesi F, Dioni I, Tommasi C, Alcaro MC, Paolini I, Barbetti F, et al. Antibodies from patients with rheumatoid arthritis target citrullinated histone 4 contained in neutrophils extracellular traps. Ann Rheum Dis. 2014; 73(7):1414-1422. doi:10.1136/ annrheumdis-2012-202765.

77. Khandpur R, Carmona-Rivera C, Vivekanandan-Giri A, Gizinski A, Yalavarthi S, Knight JS et al. NETs are a source of citrullinated autoantigens and stimulate inflammatory responses in rheumatoid arthritis. Sci Transl Med. 2013; 5(178):178ra40. doi:10.1126/ scitranslmed.3005580.

78. Pieterse E, Hofstra J, Berden J, Herrmann M, Dieker J, van der Vlag J. Acetylated histones contribute to the immunostimulatory potential of neutrophil extracellular traps in systemic lupus erythematosus. Clin Exp Immunol. 2015; 179(1):68-74. doi:10.1111/cei.12359.

79. Kim T, Kanayama Y, Negoro N, Okamura M, Takeda T, Inoue T. Serum levels of interferons in patients with systemic lupus erythematosus. Clin Exp Immunol. 1987; 70(3):562-569.

80. Ytterberg SR, Schnitzer TJ. Serum interferon levels in patients with systemic lupus erythematosus. Arthritis Rheum. 1982; 25(4):401406.

81. Jabs WJ, Hennig C, Zawatzky R, Kirchner H. Failure to detect antiviral activity in serum and plasma of healthy individuals displaying high activity in ELISA for IFN-alpha and IFN-beta. Journal of interferon \& cytokine research : the official journal of the International Society for Interferon and Cytokine Research. 1999;19(5):463-9. doi:10.1089/107999099313901.

82. Feng X, Wu H, Grossman JM, Hanvivadhanakul P, FitzGerald JD, Park GS, et al. Association of increased interferon-inducible gene expression with disease activity and lupus nephritis in patients with systemic lupus erythematosus. Arthritis Rheum. 2006; 54(9):29512962. doi:10.1002/art.22044.

83. Landolt-Marticorena C, Bonventi G, Lubovich A, Ferguson C, Unnithan T, Su J, et al. Lack of association between the interferonalpha signature and longitudinal changes in disease activity in systemic lupus erythematosus. Ann Rheum Dis. 2009; 68(9):14401446. doi:10.1136/ard.2008.093146.

84. Biesen R, Demir C, Barkhudarova F, Grun JR, Steinbrich-Zollner M, Backhaus M, et al. Sialic acid-binding Ig-like lectin 1 expression in inflammatory and resident monocytes is a potential biomarker for monitoring disease activity and success of therapy in systemic lupus erythematosus. Arthritis Rheum. 2008; 58(4):1136-1145. doi:10.1002/art.23404.

85. Rose T, Grutzkau A, Hirseland H, Huscher D, Dahnrich C, Dzionek A, et al. IFNalpha and its response proteins, IP-10 and SIGLEC-1, are biomarkers of disease activity in systemic lupus erythematosus. Ann Rheum Dis. 2013; 72(10):1639-1645. doi:10.1136/ annrheumdis-2012-201586.

86. Li Y, Lee PY, Sobel ES, Narain S, Satoh M, Segal MS, et al. Increased expression of FcgammaRI/CD64 on circulating monocytes parallels ongoing inflammation and nephritis in lupus. Arthritis Res Ther. 2009; 11(1):R6. doi:10.1186/ar2590.

87. Li Y, Lee PY, Kellner ES, Paulus M, Switanek J, Xu Y, et al. Monocyte surface expression of Fcgamma receptor RI (CD64), a biomarker reflecting type-I interferon levels in systemic lupus erythematosus. Arthritis Res Ther. 2010; 12(3):R90. doi:10.1186/ar3017.

88. Zhao M, Zhou Y, Zhu B, Wan M, Jiang T, Tan Q et al. IFI44L promoter methylation as a blood biomarker for systemic lupus erythematosus. Ann Rheum Dis. 2016; 75(11):1998-2006. doi:10.1136/ 
annrheumdis-2015-208410.

89. Wenzel J, Tuting T. An IFN-associated cytotoxic cellular immune response against viral, self-, or tumor antigens is a common pathogenetic feature in "interface dermatitis". J Invest Dermatol. 2008; 128(10):2392-2402. doi:10.1038/jid.2008.96.

90. Wenzel J, Uerlich M, Worrenkamper E, Freutel S, Bieber T, Tuting T. Scarring skin lesions of discoid lupus erythematosus are characterized by high numbers of skin-homing cytotoxic lymphocytes associated with strong expression of the type I interferon-induced protein MxA. Br J Dermatol. 2005; 153(5):1011-1015. doi:10.1111/ j.1365-2133.2005.06784.x.

91. Wenzel J, Proelss J, Wiechert A, Zahn S, Bieber T, Tuting T. CXCR3-mediated recruitment of cytotoxic lymphocytes in lupus erythematosus profundus. J Am Acad Dermatol. 2007; 56(4):648650. doi:10.1016/j.jaad.2006.08.014.

92. Wenzel J, Zahn S, Mikus S, Wiechert A, Bieber T, Tuting T. The expression pattern of interferon-inducible proteins reflects the characteristic histological distribution of infiltrating immune cells in different cutaneous lupus erythematosus subsets. Br J Dermatol. 2007; 157(4):752-757. doi:10.1111/j.1365-2133.2007.08137.x.

93. McBride JM, Jiang J, Abbas AR, Morimoto A, Li J, Maciuca R, et al. Safety and pharmacodynamics of rontalizumab in patients with systemic lupus erythematosus: results of a phase I, placebocontrolled, double-blind, dose-escalation study. Arthritis Rheum. 2012; 64(11):3666-3676. doi:10.1002/art.34632.

94. Merrill JT, Wallace DJ, Petri M, Kirou KA, Yao Y, White WI, et al. Safety profile and clinical activity of sifalimumab, a fully human anti-interferon alpha monoclonal antibody, in systemic lupus erythematosus: a phase I, multicentre, double-blind randomised study. Ann Rheum Dis. 2011; 70(11):1905-1913. doi:10.1136/ ard.2010.144485.

95. Yao Y, Richman L, Higgs BW, Morehouse CA, de los Reyes M, Brohawn $\mathrm{P}$, et al. Neutralization of interferon-alpha/beta-inducible genes and downstream effect in a phase I trial of an anti-interferon-alpha monoclonal antibody in systemic lupus erythematosus. Arthritis Rheum. 2009; 60(6):1785-1796. doi:10.1002/art.24557.

96. Petri M, Wallace DJ, Spindler A, Chindalore V, Kalunian K, Mysler E, et al. Sifalimumab, a human anti-interferon-alpha monoclonal antibody, in systemic lupus erythematosus: a phase I randomized, controlled, dose-escalation study. Arthritis Rheum. 2013; 65(4):1011-1021. doi:10.1002/art.37824.

97. Furie R, Merrill J, Werth V, Khamashta M, Kalunian K, Brohawn $\mathrm{P}$ et al. Anifrolumab, an Anti-Interferon Alpha Receptor Monoclonal Antibody, in Moderate to Severe Systemic Lupus Erythematosus (SLE). ACR/ARHP Annual Meeting: Arthritis Rheumatol. 2017; 69(2):376-386. doi: 10.1002/art.39962.

98. Zagury D, Le Buanec H, Mathian A, Larcier P, Burnett R, Amoura Z, et al. IFNalpha kinoid vaccine-induced neutralizing antibodies prevent clinical manifestations in a lupus flare murine model. Proc Natl Acad Sci U S A. 2009;106(13):5294-5299. doi:10.1073/pnas.0900615106.

99. Ducreux J, Houssiau FA, Vandepapeliere P, Jorgensen C, Lazaro E, Spertini F, et al. Interferon alpha kinoid induces neutralizing anti-interferon alpha antibodies that decrease the expression of interferon-induced and B cell activation associated transcripts: analysis of extended follow-up data from the interferon alpha kinoid phase I/II study. Rheumatology (Oxford). 2016; 55(10):1901-1905. doi:10.1093/rheumatology/kew262.

100.Zhu FG, Jiang W, Bhagat L, Wang D, Yu D, Tang JX, et al. A novel antagonist of Toll-like receptors 7, 8 and 9 suppresses lupus diseaseassociated parameters in NZBW/F1 mice. Autoimmunity. 2013; 46(7):419-428. doi:10.3109/08916934.2013.798651.

101.Guiducci C, Gong M, Xu Z, Gill M, Chaussabel D, Meeker T, et al. TLR recognition of self nucleic acids hampers glucocorticoid activity in lupus. Nature. 2010; 465(7300):937-941. doi:10.1038/ nature09102.

102.Wu YW, Tang W, Zuo JP. Toll-like receptors: potential targets for lupus treatment. Acta Pharmacol Sin. 2015; 36(12):1395-1407. doi:10.1038/aps.2015.91.

103.Sthoeger ZM, Bezalel S, Chapnik N, Asher I, Froy O. High alpha-defensin levels in patients with systemic lupus erythematosus. Immunology. 2009; 127(1):116-122. doi:10.1111/j.1365-2567.2008.02997.x.

104.Cheng FJ, Zhou XJ, Zhao YF, Zhao MH, Zhang H. Human neutrophil peptide 1-3, a component of the neutrophil extracellular trap, as a potential biomarker of lupus nephritis. International journal of rheumatic diseases. Int J Rheum Dis. 2015; 18(5):533-540. doi:10.1111/1756-185X.12433.

105. Yang CC,HsiehSC, Li KJ, Wu CH, Lu MC, Tsai CY, etal. Urinary neutrophil gelatinase-associated lipocalin is a potential biomarker for renal damage in patients with systemic lupus erythematosus. J Biomed Biotechnol. 2012; 2012:759313. doi:10.1155/2012/759313.

106.Hammad A, Mosaad Y, Elhanbly S, Youssef H, El Refaaey A, Elhusseini F, et al. Urinary neutrophil gelatinase-associated lipocalin as a marker of severe lupus nephritis in children. Lupus. 2013; 22(5):486-491. doi:10.1177/0961203313479419.

107.Torres-Salido MT, Cortes-Hernandez J, Vidal X, Pedrosa A, VilardellTarres M, Ordi-Ros J. Neutrophil gelatinase-associated lipocalin as a biomarker for lupus nephritis. Nephrol Dial Transplant. 2014; 29(9):1740-1749. doi:10.1093/ndt/gfu062.

108.Elewa EA, El Tokhy MA, Fathy SE, Talaat AM. Predictive role of urinary neutrophil gelatinase-associated lipocalin in lupus nephritis. Lupus. 2015; 24(2):138-146. doi:10.1177/0961203314550225.

109.Fang YG, Chen NN, Cheng YB, Sun SJ, Li HX, Sun F, et al. Urinary neutrophil gelatinase-associated lipocalin for diagnosis and estimating activity in lupus nephritis: a meta-analysis. Lupus. 2015; 24(14):1529-1539. doi:10.1177/0961203315600244.

110.Yara Tawfika RMS, Sherif R. El-Bassionya, Salah Hawasa, Narmen Effatb. Urinary and serum neutrophil gelatinase-associated lipocalin as a biomarker in Egyptian systemic lupus erythematosus patients: Relation to lupus nephritis and disease activity. The Egyptian Rheumatologist. 2015; 37(4):S25-S31. doi:10.1016/j. ejr.2015.09.003.

111.Li Y, Hu F, Dai Y, Li R, Ma X, Du Y, et al. Serum anti-lipocalin 2 IgG is a novel biomarker in the diagnosis of systemic lupus erythematosus. Lupus. 2014; 23(9):868-875. doi:10.1177/0961203314530484.

112.Lipsker D, Saurat JH. Neutrophilic cutaneous lupus erythematosus. At the edge between innate and acquired immunity? Dermatology. 2008; 216(4):283-286. doi:10.1159/000113940.

113.Tsuji H, Yoshifuji H, Nakashima R, Imura Y, Yukawa N, Ohmura K, et al. Sweet's syndrome associated with systemic lupus erythematosus: a case report and review of the literature. J Dermatol. 2013; 40 (8):641- 
648. doi:10.1111/1346-8138.12184.

114.Smith CK, Vivekanandan-Giri A, Tang C, Knight JS, Mathew A, Padilla RL, et al. Neutrophil extracellular trap-derived enzymes oxidize high-density lipoprotein: an additional proatherogenic mechanism in systemic lupus erythematosus. Arthritis Rheumatol. 2014; 66(9):2532-2544. doi:10.1002/art.38703.

115.Taylor PR, Bonfield TL, Chmiel JF, Pearlman E. Neutrophils from F508del cystic fibrosis patients produce IL-17A and express IL-23 dependent IL-17RC. Clin Immunol. 2016; 170:53-60. doi:10.1016/j. clim.2016.03.016.

116.Lopez P, Rodriguez-Carrio J, Caminal-Montero L, Mozo L, Suarez A. A pathogenic IFNalpha, BLyS and IL-17 axis in Systemic Lupus Erythematosus patients. Sci Rep. 2016; 6:20651. doi:10.1038/ srep20651.

117.Romero V, Fert-Bober J, Nigrovic PA, Darrah E, Haque UJ, Lee DM, et al. Immune-mediated pore-forming pathways induce cellular hypercitrullination and generate citrullinated autoantigens in rheumatoid arthritis. Science translational medicine. 2013; 5(209):209ra150. doi:10.1126/scitranslmed.3006869.

118.Knight JS, Zhao W, Luo W, Subramanian V, O’Dell AA, Yalavarthi S, et al. Peptidylarginine deiminase inhibition is immunomodulatory and vasculoprotective in murine lupus. J Clin Invest. 2013; 123(7):29812993. doi:10.1172/JCI67390.

119.Knight JS, Subramanian V, O’Dell AA, Yalavarthi S, Zhao W, Smith CK et al. Peptidylarginine deiminase inhibition disrupts NET formation and protects against kidney, skin and vascular disease in lupusprone MRL/lpr mice. Ann Rheum Dis. 2015; 74(12):2199-2206. doi:10.1136/annrheumdis-2014-205365.
120.Pescovitz MD. Rituximab, an anti-cd20 monoclonal antibody: history and mechanism of action. Am J Transplant. 2006; 6(5 Pt 1):859-866. doi:10.1111/j.1600-6143.2006.01288.x.

121.Mysler EF, Spindler AJ, Guzman R, Bijl M, Jayne D, Furie RA et al Efficacy and safety of ocrelizumab in active proliferative lupus nephritis: results from a randomized, double-blind, phase III study. Arthritis Rheum. 2013; 65(9):2368-2379. doi:10.1002/art.38037.

122.Reddy V, Jayne D, Close D, Isenberg D. B-cell depletion in SLE: clinical and trial experience with rituximab and ocrelizumab and implications for study design. Arthritis Res Ther. 2013;15 Suppl 1:S2. doi:10.1186/ar3910.

123.Furie R, Toder K, Zapantis E. Lessons Learned From the Clinical Trials of Novel Biologics and Small Molecules in Lupus Nephritis. Semin Nephrol. 2015; 35(5):509-520. doi:10.1016/j. semnephrol.2015.08.012.

124.Lazaro E, Scherlinger M, Truchetet ME, Chiche L, Schaeverbeke T, Blanco P, et al. Biotherapies in systemic lupus erythematosus: New targets. Joint Bone Spine. 2017; 84(3):267-274. doi:10.1016/j. jbspin.2016.07.004.

125.Boumpas DT, Furie R, Manzi S, Illei GG, Wallace DJ, Balow JE, et al. A short course of BG9588 (anti-CD40 ligand antibody) improves serologic activity and decreases hematuria in patients with proliferative lupus glomerulonephritis. Arthritis Rheum. 2003; 48(3):719-727. doi:10.1002/art.10856.

126.Yildirim-Toruner C, Diamond B. Current and novel therapeutics in the treatment of systemic lupus erythematosus. J Allergy Clin Immunol. 2011; 127(2):303-312; quiz 313-4. doi:10.1016/j.jaci.2010.12.1087.

127.Mok CC. Current role of rituximab in systemic lupus erythematosus. International journal of rheumatic diseases. 2015; 18(2):154-163. doi:10.1111/1756-185X.12463. 